\title{
THE AGGREGATION OF CHAULIOGNATHUS SPECIES (COLEOPTERA, CANTHARIDAE) AND ITS POSSIBLE ROLE FOR COEXISTENCE AND MIMICRY
}

\author{
Vilmar Machado ${ }^{1}$ \\ Aldo Mellender de Araújo ${ }^{2}$
}

\begin{abstract}
The relative population sizes of a species complex of Chauliognathus are reported, as well as their spatial distribution associated with different patches of food plants. Field work was done at Fazenda Santa Isabel, municipality of Guaíba, State of Rio Grande do Sul, Brazil. The results suggest that two mechanisms account for the reduction in food competition among the species involved: one is asynchrony in the appearance of the species in the area, and the other is aggregation in different patches of food plants. Since the species here reported show a similar colour pattern (yellow-black) the possibility of the occurrence of serial mimicry in this complex of species is dicussed.
\end{abstract}

KEYWORDS. Chauliognathus, aggregation, competition, mimicry, Coleoptera.

\section{INTRODUCTION}

Aggregation on food sources has been registered for several insect species. Frequently such aggregations consist of species of the same genus (AtKInsON \& SHORROCKs, 1984; Rosewell et al., 1990; Blossey, 1995). For aposematic organisms this behavior is commonly associated with an increase in protection against visually oriented predators (Sillen-Tulberg \& Hunter, 1996). Large aggregations could increase inter- and intraspecific competition. According to the principle of competitive exclusion, the coexistence of two competing species that are regulated by their shared resources implies a differentiation in their realized niche, otherwise one of them will be eliminated (BEGON et al., 1996).

This paper deals with aggregates of thousands of individuals of six species of Chauliognathus Hentz, 1930 on their food plants. The species here reported belong to a mimicry complex that are here referred as "yellow-black". Data on the recruitment rates of the species Chauliognathus flavipes Fabricius, 1781, C. expansus Waterhouse, 1878, C. octomaculatus Pic, 1915, C. fallax Germar, 1824, C. lineatus Zwetsch \& Machado, 2000 and C. tetrapunctatus Zwetsch \& Machado, 2000 are reported. Information on their spatial distribution, associated with different patches of food plants are also analyzed. Other species of Chauliognathus occurred sporadically in the area; however they did not belong to the "yellow-black" mimicry complex.

\section{MATERIAL AND METHODS}

The field work was done at Fazenda Santa Isabel, Municipality of Guaíba (30 $05^{\prime}$ S; $51^{\circ} 24^{\prime}$ W), State of Rio Grande do Sul, Brazil. Two adjacent areas were initially surveyed one day over eleven consecutive weeks between October 17, 1996 and January 2, 1997. Lately they were joined since the results did not differ statistically. The total area had about one hectare and was formed by grass and patches of Eryngium elegans Cham. \& Schlecht (Umbelliferae) one of the food plants utilized by Chauliognathus spp. Beetles first to appear, Chauliognathus

1. Laboratório de Biologia Molecular, Universidade do Vale do Rio dos Sinos, UNISINOS, C.P. 275, CEP 93022-000, São Leopoldo, RS, Brasil.

2. Departamento de Genética, Universidade Federal do Rio Grande do Sul, UFRGS, C.P. 15053, CEP 91501-970, Porto Alegre, RS, Brasil. 
fallax, were observed on November 11 (which, from here on is considered week 1). In the sixth week of sampling, when all species were present and maximum density of soldier beetles was observed, the area was divided according to the number of Eryngium patches present in order to ascertain the frequency of each species of soldier beetle per patch. Six of such patches were found, their area ranging from 12 to $19 \mathrm{~m}^{2}$. All insects were captured by hand from 10 am to noon, scored for elytra phenotype, sex, and the majority of them released (two new species are described in ZwETSCH \& MACHADO, 2000). For the statistical analysis of the species aggregation was used the KolmogorovSmirnov non-parametric test. Although this test assumes a continuously distribution variable, it can also be used for a discrete one, with the advantage that classes with small number of individuals need not to be lumped (SoKAL \& ROHLF, 1969).

Some specimens are deposited in the collection of Laboratório de Genética, Universidade do Vale do Rio dos Sinos, São Leopoldo, Rio Grande do Sul, Brazil.

\section{RESULTS}

The first beetles to appear in the area ( C. fallax) fed the pollen of flowers of Myrceugenia campestris Legran \& Kausel (Myrtaceae) and secondarily of pollen of the hemiparasite Struthanthus polyrhizus Martius (Loranthaceae). In the following week they moved to Eryngium sp. where they remained until their disappearance from the area, on December 26 (we extended the observations an additional week to confirm the absence of adults) correlated with the end of the Eryngium flowering period.

Table I. Number and relative frequency (per week) of six Chauliognathus species collected at Fazenda Santa Isabel, Guaíba, RS.

\begin{tabular}{|c|c|c|c|c|c|c|c|c|c|c|c|c|c|c|c|c|c|}
\hline Species/weeks & 1 & & 2 & & 3 & & 4 & & 5 & & 6 & & 7 & & 8 & & $\mathrm{~T}$ \\
\hline C. expansus & 0 & - & 0 & - & 0 & - & 0 & - & 2 & $<0.01$ & 33 & 0.03 & 32 & 0.04 & 1 & $<0.01$ & 68 \\
\hline C. fallax & 76 & 1.00 & 244 & 1.00 & 565 & 0.97 & 607 & 0.97 & 624 & 0.77 & 361 & 0.33 & 619 & 0.68 & 212 & 0.71 & 3308 \\
\hline C. flavipes & 0 & - & 2 & - & 15 & 0.03 & 16 & 0.03 & 107 & 0.13 & 606 & 0.54 & 135 & 0.15 & 63 & 0.21 & 944 \\
\hline C. lineatus & 0 & - & 0 & - & 0 & - & 0 & - & 0 & - & 26 & 0.02 & 0 & - & 0 & - & 26 \\
\hline C. octomaculatus & 0 & - & 0 & - & 0 & - & 0 & - & 54 & 0.07 & 39 & 0.04 & 90 & 0.10 & 18 & 0.06 & 201 \\
\hline C. tetrapunctatus & 0 & - & 0 & - & 0 & - & 0 & - & 6 & $<0.01$ & 39 & 0.04 & 27 & 0.03 & 4 & 0.01 & 76 \\
\hline TOTAL & 76 & & 246 & & 580 & & 623 & & 793 & & 1104 & & 903 & & 298 & & 4623 \\
\hline
\end{tabular}

The number and the relative frequency of insects of each species collected in successive weeks (tab. I) show that from the first week until the fourth, C. fallax stands as the dominant. Afterwards there occurred a progressive increase in the other species, mainly $C$. flavipes, and by the sixth week the maximum total density is attained as well as maximum diversity. The changes in relative population size of each species (fig. 1) show that $C$. fallax, for instance, has a stable size from the third week until the seven. This pattern contrasts with the one for Chauliognathus tetrapunctatus, which has peaks at the sixth week, although in each sample its percentage is very low (incidentally, the same occurs for other species poorly represented in each sample). As can be seen, four species have peaks at the sixth week, an aspect later discussed in relation to the mimicry hypothesis.

At the sixth week of observations when the maximum density and diversity of species were observed, we decided to investigate whether the different species were independently distributed among the Eryngium patches (tab. II). When all six species are taken

Table II. Number of individuals of the six Chauliognathus species found in different patches in the sixth week of sampling at Fazenda Santa Isabel, Guaíba, RS, between October 1996 and January, 1997.

\begin{tabular}{lrrrrrrr}
\hline \multicolumn{1}{c}{ Species/patches } & P1 & P2 & P3 & P4 & P5 & P6 & Total \\
\hline C. expansus & 3 & 11 & 2 & 11 & 0 & 6 & 33 \\
C. fallax & 39 & 41 & 16 & 68 & 79 & 118 & 361 \\
C. flavipes & 125 & 130 & 44 & 149 & 56 & 102 & 606 \\
C. lineatus & 9 & 3 & 7 & 9 & 2 & 9 & 39 \\
C. octomaculatus & 4 & 4 & 1 & 13 & 11 & 6 & 39 \\
C. tetrapunctatus & 2 & 16 & 1 & 2 & 3 & 2 & 26 \\
\hline TOTAL & 182 & 205 & 71 & 252 & 151 & 243 & 1104 \\
\hline
\end{tabular}




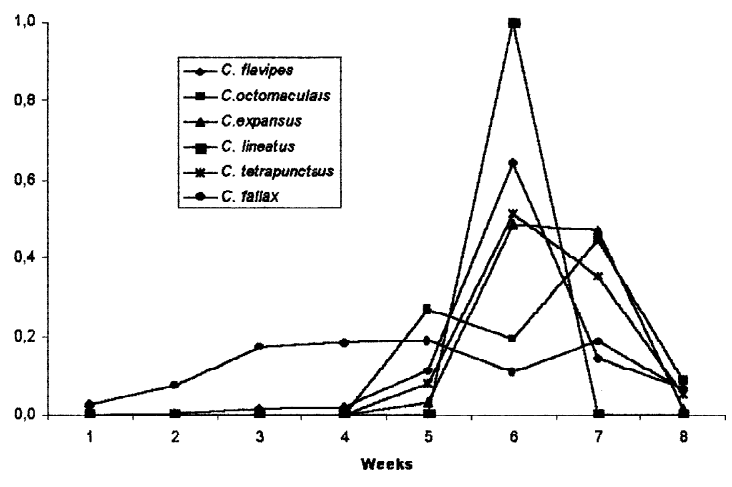

Fig. 1. Proportion of captured individuals of the six species (y axis), along eight consecutive weeks (abcissa) at Fazenda Santa Isabel, Guaíba, RS. together there is a highly significant species $\mathrm{X}$ patch association $\left(\mathrm{X}^{2}=154.39\right.$; 25 d.f.; $\mathrm{p}<0.001)$; if the comparison is made only with the two commoner species ( $C$. flavipes and $C$. fallax) the differences are still significant, indicating the association of them with one or more patches of Eryngium sp. $\left(\mathrm{X}^{2}=83.06 ; 5\right.$ d.f.; $\left.\mathrm{p}<0.001\right)$. The association still persists when the remaining four species are compared $\left(\mathrm{X}^{2}=55.90 ; 15\right.$ d.f.; $\mathrm{p}<0.01)$. Given that an association was detected it should be important to investigate whether it was with the same or different patch of Eryngium. This was done by using intra-specific comparisons with Kolmogorov-Smirnov hypothesis testing (null hypothesis: equal expected proportions of insects for each patch). For $C$. flavipes the maximum difference was at patch 2 (P2 in Table $2 ; \mathrm{d}^{\max }=0.087, \mathrm{p}<0.01$ ); as for $C$. fallax it was at P3 ( $\left.\mathrm{d}^{\max }=0.234 ; \mathrm{p}<0.01\right)$; the significance vanishes when the remaining four species are summed up.

\section{DISCUSSION}

The results here reported could be viewed in the light of two ecological-evolutionary theories: competition and mimicry (Blossey, 1995; Sillen-Tulberg \& Hunter, 1996). The findings suggest that two mechanisms could account for the reduction in the food competition among the species involved (or at least could facilitate their coexistence); one is the asynchrony in the appearance of the species in the area. C. fallax appears early and rapidly increases in number of individuals; $C$. flavipes has a short period of abundance, while $C$. expansus, $C$. octomaculatus, $C$. lineatus and $C$. tetrapunctatus represent minor components of the group, as far as number of individuals is concerned. The other finding that facilitates coexistence (and consequently reduces the competition between the species) is their aggregation in different patches of Eryngium sp., during the maximum diversity period (sixth week). AtKinson \& SHorrocks (1984) found that the aggregation of larval diptera over discrete and ephemeral breeding sites enhanced their coexistence, which is in accordance with theoreticall predictions (DE JoNG, 1979; HANSKI, 1981). In the present study, C. flavipes and C. fallax are not equally distributed among the patches (based on Kolmogorov-Smirnov test). The maximum difference between expected and observed for $C$. flavipes occurred at patch $2(\mathrm{P} 2)$, while for $C$. fallax it occurred at P3. The other four species, taken together, did not show evidence of an unequal distribution per patch (they correspond to only $8 \%$ of the total number of individuals in the area).

The role interspecific competition play in the shaping of insect communities have 
oscilated from a fundamental one to a total discredited. However, a recent review reevaluate the importance of this kind of interaction (DenNo et al., 1995). These authors found that in 193 pair-wise species interactions, $76 \%$ showed evidence that competition was important (148 of them were experimental demonstrations); moreover, the different guilds examined (sap feeders, stem borers, free-living) showed different degrees of competition, being least likely between free-living.

Another aspect of the present findings is the possibility of the occurrence of serial mimicry as reported by WALDBAUER (1988). Because Chauliognathus species appear in the area asynchronously, this could afford greater protection to the less abundant species. Chauliognathus fallax is the first to appear, followed by C. flavipes, which increases substantially by the $5^{\text {th }}$ week. Together they comprise $92 \%$ of the individuals. The remaining four species may gain extra protection despite their lower numbers by appearing latter after predators have had an opportunity to learn to avoid the colour pattern (the species here reported are part of a Müllerian mimicry complex). Although appearing in the area at different times they showed, at the $6^{\text {th }}$ week of observation a great aggregation of more than a thousand beetles, which, in aposematic species, after Sillen-Tulberg \& Hunter (1996) increases their defensive advantages. The movement of insects in the area along the weeks seems to be related to the quality of the food sources. Whenever the plants showed signs of unsuitable conditions (dryness), they were abandoned by the soldier beetles.

\section{REFERENCES}

AtKInson, W. D. \& ShorRocks, B. 1984. Aggregation of larval diptera over discrete and ephemeral breeding sites: the implications for coexistence. Am. Nat., Chicago, 124:336-351.

Begon, M.; Mortimer, M. \& Thompson, D. J. 1996. Population Ecology. Cambridge, Blackwell Science. 247p.

Blossey, B. 1995. Coexistence of two leaf-beetles in the same fundamental niche. Distribution, adult phenology and oviposition. Oikos, Copenhagen, 74:225-234.

DE Jong, G. 1979. The influence of the distribution of juveniles over patches of food on the dynamics of a population. Neth. J.Zool., Leiden, 29:33-51.

DenNo, R. F.; Mcclure, M.S. \& Ott, J.R. 1995. Interspecific interactions in phytophagous insects: Competition reexamined and resurrected. A. Rev. Ent., Palo Alto, 40:297-331.

HANSKI, I. 1981. Coexistence of competitors in patchy environments with and without predation. Oikos, Copenhagen, 38:210-221.

Rosewell, J.; Shorrocks, B. \& Edwards, K. 1990. Competition on a divided and ephemeral resource: testing the assumptions. I. Aggregation. J. Anim. Ecol., London, 59:977-1001.

Sillen-Tulberg, B. S. \& Hunter, A. F. 1996. Evolution of larval gregariousness in relation to repellent defence and warning coloration in tree-feeding macrolepidoptera: a phylogenetic analysis based on independent contrasts. Biol. J. Linn Soc., London, 57:253-276.

Sokal, R. R. \& RohlF, F. J. 1969. Biometry. San Francisco, W. H. Freeman. 776p.

WaldBAUER, G. P. 1988. Asynchrony between mimics and their models. Am. Nat., Chicago, 131(supplement): 103121.

ZwETSCh, A. \& MAchado, V. 2000. Estudo morfológico do aedeagus das espécies de Chauliognathus Hentz, 1830 (Coleoptera; Cantharidae) do complexo "amarelo-preto". Acta Biologica Leopoldensia, São Leopoldo, 22(2): 193-203.

Recebido em 14.05.1999; aceito em 27.12.1999. 